\title{
Loss of abdominal fat and improvement of the cardiovascular risk profile by regular moderate exercise training in patients with NIDDM
}

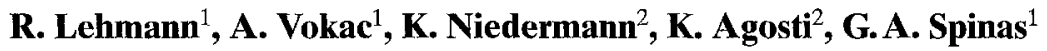 \\ ${ }^{1}$ Department of Internal Medicine, Division of Endocrinology and Metabolism, University Hospital Zürich, Zürich Switzerland \\ ${ }^{2}$ Department of Rheumatology and Institute for Physical Therapy, University Hospital Zürich, Zürich Switzerland
}

Summary Non-insulin-dependent diabetes mellitus (NIDDM) is associated with an increased cardiovascular risk. Glycaemic control alone is often insufficient to control diabetic dyslipidaemia and other cardiovascular risk factors associated with NIDDM. The present trial was designed to evaluate the effects of physical activity as an adjunct to standard diabetes therapy on the lipid profile, blood pressure, glycaemic control, weight and body fat. Sixteen well-controlled $\left(\mathrm{HbA}_{1 \mathrm{c}} 7.5 \%\right)$ patients with NIDDM participated in a regular aerobic exercise training programme at $50-70 \%$ maximal effort over 3 months. Thirteen age- and sex-matched patients with NIDDM served as a control group. The 3 -month intervention with an increase in physical activity from 92 (mean $\pm \mathrm{SD}) \pm 79$ to $246 \pm 112 \mathrm{~min}$ per week $(p<0.001)$ by means of a structured activity programme resulted in significant improvement of plasma lipids with a $20 \%$ decrease in triglycerides $(p<0.05)$, unchanged total cholesterol and increases in high-density lipoprotein and high-density lipoprotein-3 subfraction of $23 \%(p<0.001)$ and $26 \%$ $(p<0.001)$, respectively. Systolic and diastolic blood pressure decreased significantly from $138 \pm 16$ to $130 \pm 17 \mathrm{~mm} \mathrm{Hg} \quad(p<0.05)$ and $88 \pm 10$ to $80 \pm$ $10 \mathrm{mmHg}(p<0.001)$, respectively. Resting heart rate decreased from $81 \pm 13$ to $74 \pm 14$ beats per minute $(p<0.001)$, waist-hip circumference ratio decreased from $0.96 \pm 0.11$ to $0.92 \pm 0.10 \quad(p<0.001)$ and body fat decreased from $35.3 \pm 7.2$ to $33.0 \pm 8.0 \%(p<0.001)$. These effects occurred independently of changes in body weight and glycaemic control, which did not change during the study. This study shows that improvement in physical fitness by introducing regular physical exercise as part of the treatment programme in patients with NIDDM results in a significant amelioration of their cardiovascular risk profile. [Diabetologia (1995) 38: 13131319]

Key words Exercise, non-insulin-dependent diabetes mellitus, abdominal fat, blood pressure, heart rate, cholesterol, high-density lipoprotein, high-density lipoprotein-2, high-density lipoprotein-3, triglycerides.
Diabetes mellitus is associated with a three- to fivefold increased risk for coronary heart disease (CHD)

Received: 16 February 1995 and in revised form: 4 May 1995

Corresponding author: Dr. R. Lehmann, Division of Endocrinology and Metabolism, Department of Internal Medicine, University Hospital Zürich, Raemistrasse 100, CH-8091 Zurich, Switzerland

Abbreviations: NIDDM, Non-insulin-dependent diabetes mellitus; CHD, coronary heart disease; HDL, high density lipoprotein; BP, blood pressure; bpm, beats per minute; MAP, mean arterial presssure; WHR, waist-hip ratio; LPL, lipoprotein lipase.
[1]. More than $50 \%$ of total mortality in diabetic patients is caused by CHD. Abnormalities of plasma lipids and lipoprotein concentrations are common findings in diabetic patients, particularly in those with poor glycaemic control. Non-insulin-dependent diabetes mellitus (NIDDM) should be considered as part of a syndrome of metabolic abnormalities that markedly increase the risk for CHD, including dyslipidaemia, insulin resistance, male-type obesity and hypertension. Thus, the focus of treatment can no longer be on glucose control only, but should be directed at correcting these risk factors. Physical training is recommended as an adjunct therapy to diet in the 
Table 1. Baseline characteristics of patients who completed the trial

\begin{tabular}{|c|c|c|}
\hline & $\begin{array}{l}\text { Intervention group } \\
(n=16)\end{array}$ & $\begin{array}{l}\text { Control group } \\
(n=13)\end{array}$ \\
\hline $\begin{array}{l}\text { Anthropometric and demographic data } \\
\text { Mean (range) age (years) } \\
\text { Male/female } \\
\text { Duration (range) of diabetes (years) } \\
\text { Body-mass index }\left(\mathrm{kg} / \mathrm{m}^{2}\right) \\
\text { Body weight }(\mathrm{kg}) \\
\% \text { body fat } \\
\text { Waist-hip ratio }\end{array}$ & $\begin{array}{l}54(42-73) \\
8 / 8 \\
7.1(1-25) \\
31.2 \pm 7.5 \\
87.3 \pm 22.3 \\
35.3 \pm 7.2 \\
0.955 \pm 0.109\end{array}$ & $\begin{array}{l}59(50-79) \\
7 / 6 \\
8.7(2-22) \\
31.3 \pm 5.2 \\
86.8 \pm 13.1 \\
33.4 \pm 7.5 \\
0.979 \pm 0.115\end{array}$ \\
\hline $\begin{array}{l}\text { History } \\
\text { Hypertension requiring treatment } \\
\text { Smokers } \\
\text { Weekly alcohol intake } 0-15 \mathrm{~g} \\
\text { Weekly alcohol intake } 15-100 \mathrm{~g} \\
\text { Weekly alcohol intake }>100 \mathrm{~g} \\
\text { Weekly physical activity (min) }\end{array}$ & $\begin{array}{l}4 \\
3 \\
9 \\
6 \\
1 \\
1 \\
\\
\\
92 \pm 79\end{array}$ & $\begin{array}{ll}6 & \\
2 & \\
7 & \\
4 & \\
2 & \\
& 96 \pm 75\end{array}$ \\
\hline $\begin{array}{l}\text { Therapy } \\
\text { Oral hypoglycaemic agents } \\
\text { Sulphonylureas (glibenclamide/gliclazide) } \\
\text { Biguanides (metformin) } \\
\text { Combination sulphonylureas/biguanides } \\
\alpha \text {-glucosidase inhibitors (acarbose) }\end{array}$ & $\begin{array}{l}10 \\
3(1 / 2) \\
3 \\
2 \\
2\end{array}$ & $\begin{array}{l}6 \\
3(1 / 2) \\
1 \\
1 \\
1\end{array}$ \\
\hline $\begin{array}{l}\text { Glycaemic control } \\
\mathrm{HbA}_{1 \mathrm{c}}(\%)(\text { normal: } 4.0-6.4 \%)\end{array}$ & $7.5 \pm 1.6$ & $7.8 \pm 1.7$ \\
\hline
\end{tabular}

Values are mean $\pm \mathrm{SD}$. $p=\mathrm{NS}$

management of NIDDM [2]. However, long-term results with exercise regimens have been disappointing, largely because of poor patient compliance [3]. Several reviews have pointed out the potential for exercise to improve not only insulin sensitivity, glucose tolerance and long-term glycaemic control in diabetic patients, but also to improve the plasma lipid profile, blood pressure and obesity $[4,5]$.

The aim of the present study was to determine the changes in glycaemic control, plasma lipids, particularly high-density lipoprotein cholesterol (HDL-C), HDL-C-subfractions and triglycerides, blood pressure, weight and abdominal fat induced by increasing the degree of physical activity in addition to standard diabetes therapy.

\section{Patients and methods}

Twenty-one patients from the Diabetes Unit of the University Hospital Zurich, aged 42 to 73 years (mean 55.5 years \pm SD 9,8, 9 women and 12 men) agreed to participate in a 3-month supervised exercise training programme. Informed consent was obtained and the study was approved by the medical ethics committee. The patients were well-controlled on standard therapy, including diet and, where appropriate, oral antidiabetic drugs (Table 1). Exclusion criteria were symptomatic CHD, autonomic neuropathy, insulin therapy, and the inability to participate in more than $80 \%$ of the training sessions. Sixteen patients completed the study (intervention group) and five patients dropped out (three were not able to attend the required number of sessions and for two the programme was too intense). Thirteen age- and gender-matched patients with the same duration of diabetes, and similar degree of physical activity at baseline served as the control group. The anthropometric and demographic data of the patients in the intervention and control group at baseline are shown in Table 1.

Study design. All patients were interviewed during the baseline visit. Information was collected on a variety of potential coronary risk factors, including hypertension, cigarette smoking, dietary intake, socio-economic status, level of physical activity, current medication, pre- or postmenopausal state, oestrogen replacement, and alcohol consumption. Average weekly alcohol intake was recorded in grams of ethanol. Three categories were defined: less than $15 \mathrm{~g}$ ethanol per week, $15 \mathrm{~g}$ or more but less than $100 \mathrm{~g}$, and more than $100 \mathrm{~g}$ per week.

Analyses were done after a 12-h overnight fast for: blood glucose, $\mathrm{HbA}_{1 \mathrm{c}}$, plasma insulin, C-peptide, total cholesterol, triglycerides, HDL-cholesterol (HDL-C), HDL2-cholesterol (HDL2-C), HDL3-cholesterol (HDL3-C), apolipoproteins $\mathrm{A}-1$ and $\mathrm{B}$, and albuminuria.

Body weight was measured to the nearest $0.1 \mathrm{~kg}$. Height was measured to the nearest centimetre. Body mass index (BMI) was calculated as weight $(\mathrm{kg}) /$ height $(\mathrm{m})^{2}$. Waist circumference was measured to the nearest 0.5 centimetre at the level of the umbilicus with the patients standing and breathing normally. Hip circumference was measured to the nearest 0.5 centimetre at the level of the greater trochanters. The average of three readings was taken as the measurement of each circumference. The readings were done by a single observer.

Body composition was assessed with a near-infrared interactance device (Futrex-5000, Futrex Inc., Gaithersburg, MD., USA), by using an average of three measurements. This technique has been previously described and validated against other techniques such as deuterium oxide dilution, skinfold thickness and ultrasound and was found to yield reproducible results [6]. In our hands intra- and interassay variation was 2.1 and $2.8 \%$, respectively. Furthermore we validated near-infra- 
red interactance against bioelectrical impedance analysis previously using the BIA 101/A, a portable bioimpedance analyser (Akern, RJL System, Detroit, MI., USA), and found a correlation coefficient of $0.97(n=40)$.

Blood pressure (BP) was recorded to the nearest $2 \mathrm{~mm} \mathrm{Hg}$ after $5 \mathrm{~min}$ in the supine position with a mercury sphygmomanometer.

Of 16 patients 13 agreed to monitor their BP for $24 \mathrm{~h}$ before and after the intervention period. BP was measured half-hourly during the subjects' estimated waking hours of between 07.00 and 22.00 hours each day and hourly for the remaining (overnight) period using an ambulatory sphygmomanometer device (SpaceLabs, 90207, Redmond, WA., USA).

All patients followed a prescribed diabetes diet with $50 \%$ carbohydrates, $35 \%$ fat and $15 \%$ protein content. The actual daily intake as assessed by a diet diary over a period of 5 days was (mean \pm SD) $1664 \pm 345 \mathrm{kcal}$ per day with $39 \%$ carbohydrates, $44 \%$ fat and $17 \%$ protein. The average daily cholesterol intake was $265 \pm 104 \mathrm{mg}$, the fibre intake $17 \pm 5.3 \mathrm{~g}$ and the average weekly alcohol intake was $24 \pm 36 \mathrm{~g}$. Diet and medication were kept unchanged throughout the study, with the exception that patients treated with sulphonylureas were advised to consume extra carbohydrates when performing exercise, in order to avoid hypoglycaemia.

Protocol of exercise programme. Patients participating in the exercise programme were evaluated for physical fitness by a step test before and after the intervention. The 3-min step test is a reliable cardiorespiratory test with minimal equipment required and was performed as described previously [7]. The heart rate was recorded at the end of the test and during the first minute while sitting, thus recording the maximal heart rate and the rate of recovery. Prior to the intervention period the patients underwent a thorough physical examination with a stress ECG until exhaustion whereby the maximal heart rate was recorded.

The physician and physical therapist gave oral instructions for effective exercise training. Thereafter, physical activity was regularly monitored by daily exercise records. The probands participated in a weekly supervised training session designed to induce and maintain physical fitness. The programme included aerobic exercise (biking on a stationary bike, rowing, skipping rope, walking, jogging, climbing stairs, gymnastics and interval training) with heart rate at $50-70 \%$ of the patients' maximal effort (according to Schneider and Ruderman) [8]. The heart rate was monitored during the $30-45 \mathrm{~min}$ aerobic training by a heart rate monitor (Polar Target, Model \#127990, Stamford, CT., USA). The rest of the 90-min programme consisted of warm-up, stretching exercises and postexercise cool-down. Exercise groups and family support were strongly encouraged and family members or friends were also invited to participate. Exercise was performed under supervision of a physician and physical therapist once weekly, and patients were encouraged to exercise on an individual basis at least 3 times a week for $30-45 \mathrm{~min}$ and record the type and time of activity in a log-book. The control group maintained their usual level of activity and diet throughout the study.

Biochemical analyses. Glucose was determined by an automated hexokinase method (HK, Uni-Kit III, Roche, Basel, Switzerland). Plasma lipids were measured in fresh plasma. Cholesterol was measured by an enzymatic colorimetric test using cholesterase, cholesterol oxidase, and aminophenazone (Cholesterol PAP, MA-kit 100, Roche), and triglycerides were determined by a colorimetric reaction with iodonitrotetrazolium chloride after enzymatic hydrolysis (Triglyceride PAP, Uni-Kit III, Roche). HDL-, HDL2- and HDL3-cholesterol were determined using a stepwise precipitation procedure with dextran/magnesium chloride and the analytical method described above for total cholesterol [9]. This stepwise HDL$\mathrm{C}$ precipitation corresponds well with HDL-C subfraction analysis by rate zonal ultracentrifugation [10]. Plasma apolipoproteins $\mathrm{A}-1$ and $\mathrm{B}$ were determined by nephelometry in a Beckman Array Protein System (Beckman Instruments, Berkeley, Calif., USA). $\mathrm{HbA}_{1 \mathrm{c}}$ was determined using an HPLC system (Biorad Diagnostics Group, Hercules, CA., USA). Plasma insulin and C-peptide were measured by radioimmunoassay (Diagnostics Products Corporation, Los Angeles, CA., USA). Albuminuria was assessed in a timed overnight urine collection by an immunoturbidimetric method (Microalb, Bayer Diagnostics, Basingstoke, UK)

\section{Statistical analysis}

Data were analysed with Statistica for Windows software (Statsoft, Inc., 1994, Tulsa, Okla., USA). Relations among variables of interest were analysed pairwise (before and after intervention) with the paired Student's $t$-test for dependent samples and, where appropriate, with the Wilcoxon matched pairs test; $p<0.05$ was considered significant.

\section{Results}

\section{Physical activity}

The mean time of weekly physical activity increased by $267 \%$ of the baseline level, persisted at a high level of $317 \%$ and was unchanged in the control group (Table 2). Physical fitness as assessed by the step test and resting heart rate changed significantly in the intervention group only (Table 2).

\section{Metabolic parameters and body composition}

Significant changes were observed in plasma lipids (HDL-C, HDL3-C, triglycerides, and apolipoprotein-A1) in the intervention group only. Total HDL$\mathrm{C}$ increased by $23 \%$ from (mean \pm SEM) $1.15 \pm 0.01$ to $1.42 \pm 0.11$ and $1.35 \pm 0.12 \mathrm{mmol} / \mathrm{l}$ at 6 -month follow-up, respectively $(p<0.001$ and $p<0.01)$. HDL3$C$ increased by $26 \%$ from $0.97 \pm 0.07$ to $1.23 \pm 0.10$ ) and $1.09 \pm 0.08 \mathrm{mmol} / 1 \quad(p<0.001$ and $p<0.01)$, respectively, while HDL2-C increased gradually from $0.17 \pm 0.05$ to $0.20 \pm 0.02$ and $0.27 \pm 0.05 \mathrm{mmol} / \mathrm{l}(p=$ 0.48 and $p=0.05$ ), respectively. Triglycerides decreased by $20 \%$ from $2.81 \pm 0.37$, to $2.24 \pm 0.27$ and $2.36 \pm 0.30 \mathrm{mmol} / \mathrm{l}(p<0.05$ and $p=0.01)$, respectively. Total cholesterol and low-density lipoprotein (LDL) remained unchanged $(5.6 \pm 0.2,5.6 \pm 0.2$, $5.5 \pm 0.2$ and $3.1 \pm 0.2,3.0 \pm 0.2,3.1 \pm 0.2 \mathrm{mmol} / \mathrm{l}$, respectively (NS), but the cholesterol/HDL-C ratio decreased significantly from $5.4 \pm 0.5$ to $4.3 \pm 0.3$ and $4.5 \pm 0.4 \quad(p<0.01$ and $p<0.001)$, respectively (Fig. 1). Apolipoprotein-A1 increased from $1.51 \pm$ 0.06 to $1.65 \pm 0.07$ and $1.60 \pm 0.06 \mathrm{~g} / \mathrm{l}$, respectively 
Table 2. Anthropometric data, fitness and metabolic data

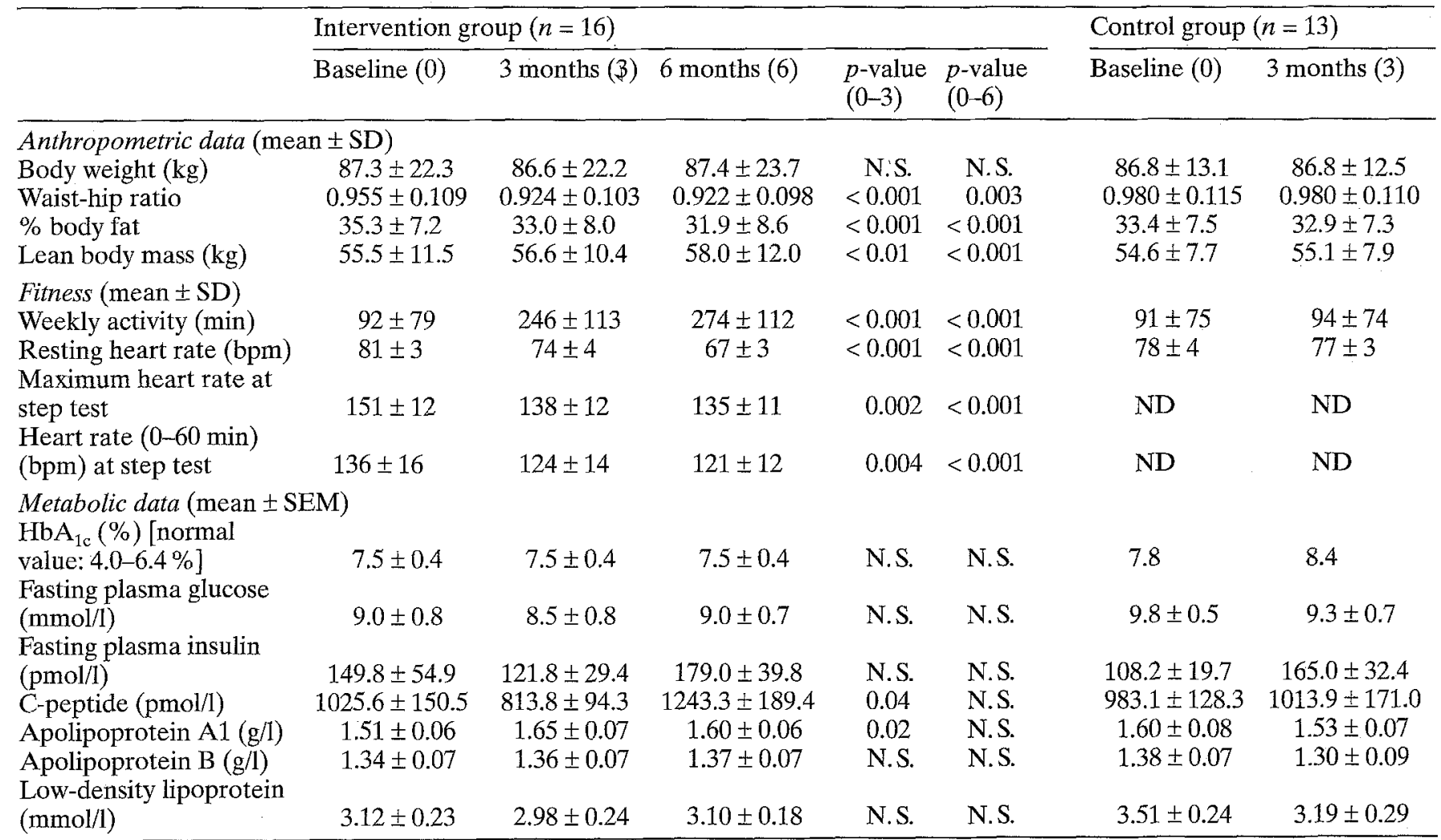

$p=$ NS for control group; ND, not determined

( $p<0.05$ and NS). No significant changes in fasting blood glucose, $\mathrm{HbA}_{1 \mathrm{c}}$, fasting insulin and C-peptide levels could be observed (Table 2).

No change in body weight was recorded, but body fat decreased from (mean \pm SD) $35.3 \pm 7.2$ to $33.0 \pm$ $8.6 \%$ and $31.9 \pm 8.6 \%$ at follow-up $(p<0.001)$ and the waist circumference decreased from $103.2 \pm 17.9$ to $100.2 \pm 17.4$ and $99.7 \pm 17.6 \mathrm{~cm}$ at follow-up ( $p<$ 0.001 ), respectively, while hip circumference remained constant $(108.215 .2,108.5 \pm 14.9$ and $108.0 \pm$ $15.5 \mathrm{~cm})$. As a consequence the waist-hip ratio (WHR) decreased significantly in the intervention group (Table 2).

Heart rate and blood pressure. A significant reduction in the diastolic and systolic BP and resting heart rate was observed at clinic readings and with ambulatory-blood pressure monitoring (ABPM). Systolic $\mathrm{BP}$ decreased from (mean $\pm \mathrm{SD}$ ) $138 \pm 16 \mathrm{~mm} \mathrm{Hg}$ (APBM: $136 \pm 11)$ to $130 \pm 16.5(126 \pm 6)$ and to $128 \pm 15(124 \pm 7) \mathrm{mm} \mathrm{Hg}$ at follow-up $(p<0.05$, $p=0.01$ and for ABPM $p<0.01$ ), while diastolic BP showed a highly significant reduction from $88 \pm 10$ $(84 \pm 8)$ to $80 \pm 10(78 \pm 9)$ and $77 \pm 6(76 \pm 9)$ at follow-up, respectively (all $p<0.001$ ) (Fig. 2). The tendency to lower the resting heart rate continued throughout the follow-up period (Table 2).
Influence of age. Data on plasma lipids, body composition, heart rate and BP were subanalysed according to the patients' age: $\geq 55$ years $(n=6)$ and $<55$ years $(n=10$, values in parentheses [. .]).

Total HDL-C increased from (mean \pm SEM) $1.15 \pm 0.08[1.15 \pm 0.12]$ to $1.38 \pm 0.08[1.48 \pm 0.14]$ and $1.33 \pm 0.10[1.39 \pm 0.14] \mathrm{mmol} / 1$ at 6 -month follow-up, respectively $(p=0.003$ and $p<0.05)$ $[p=0.01$ and $p=0.002]$. The WHR decreased from $($ mean \pm SD $) \quad 0.960 \pm 0.063 \quad[0.946 \pm 0.158]$ to $0.927 \pm 0.056 \quad[0.920 \pm 0.151]$ and $0.930 \pm 0.05$ $[0.909 \pm 0.142]$ at 6-month follow-up, respectively $(p=0.001$ and $p<0.05)[p<0.05$ and $p<0.05]$. Percentage body fat decreased from $33.9 \pm 8.3$ $[37.7( \pm 4.0)]$ to $30.5 \pm 8.5[37.3( \pm 4.9)]$ and $28.9 \pm 9.2$ $[36.3( \pm 5.1)] \%$ at follow-up $(p<0.001$ and $p<0.01)$ [NS, $p<0.05]$. Resting heart rate decreased from

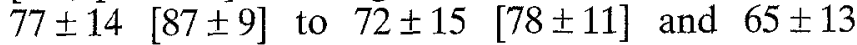
$[70 \pm 11] \mathrm{bpm}$ at follow-up, respectively $(p<0.05$ and $p=0.001[p<0.05$ and $p=0.01]$. Diastolic BP decreased from $90 \pm 11$ [86 \pm 6$]$ to $80 \pm 10[80 \pm 10]$ and $76 \pm 5[79 \pm 7] \mathrm{mmHg}$ at follow-up, respectively $(p<0.05)[p<0.05]$. 

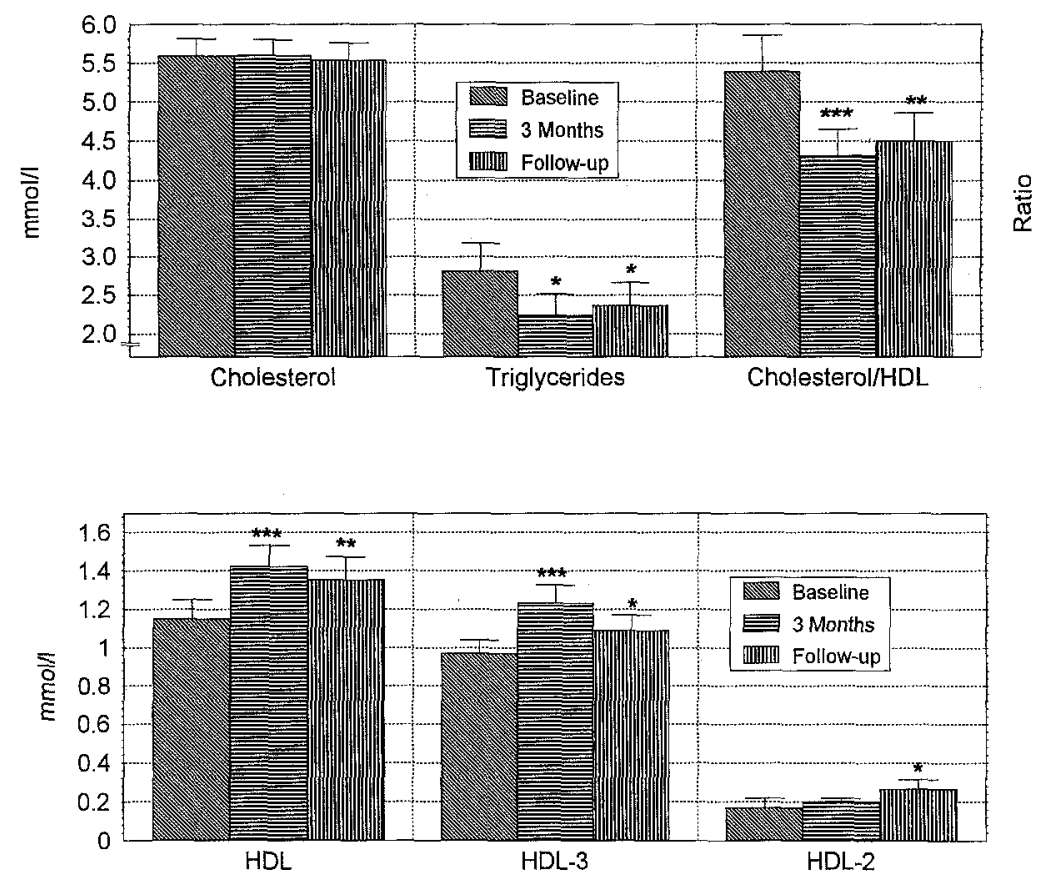

Fig. 1. Lipid profile at baseline, 3 months and 6month follow-up. Values are means \pm SEM, significant differences from baseline values: $* p \leq 0.05$, $* * p \leq 0.01, * * * p \leq 0.001$
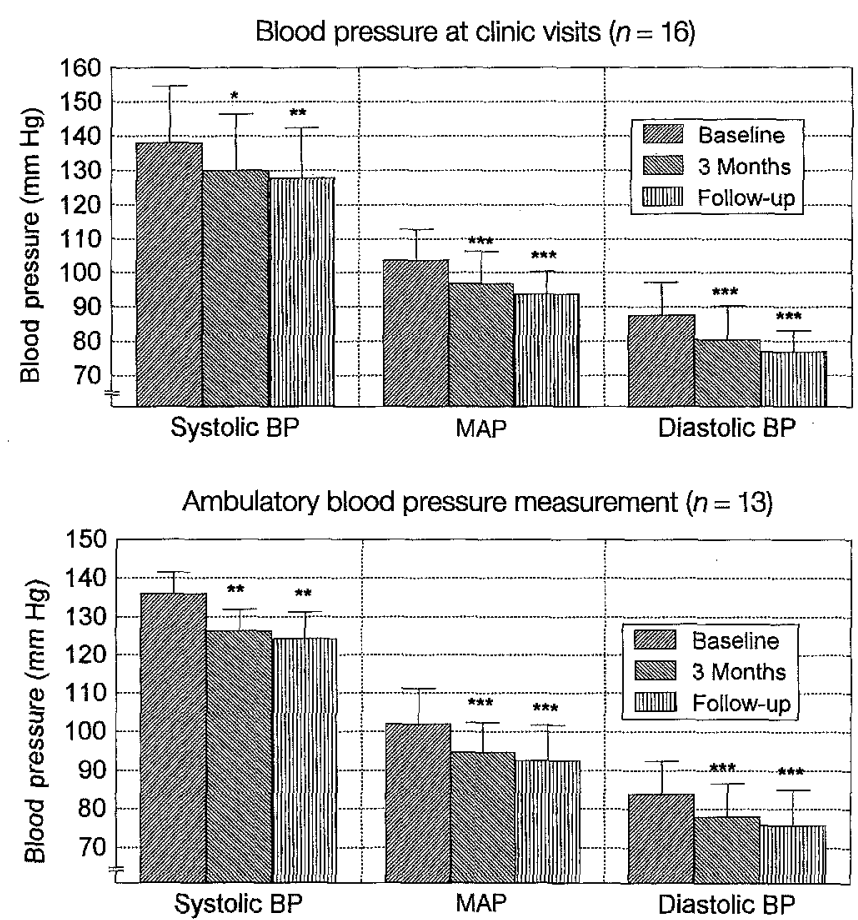

Fig. 2. Blood pressure at clinic visits and during ambulatory blood pressure measurement at baseline, 3 months and at 6month follow-up. Values are means $\pm \mathrm{SD}$, significant differences from baseline values: $* p \leq 0.05$, ** $p \leq 0.01$, *** $p \leq 0.001$

\section{Discussion}

It is commonly believed that physical training is not a feasible form of therapy for most NIDDM patients over 55 to 60 years of age, because of other interfering diseases, such as orthopaedic problems, coronary and peripheral artery disease, etc. Furthermore, poor long-term compliance was a major problem in many studies examining the effects of exercise and diet as first-line therapy for NIDDM patients $[3,4$, 11]. Nevertheless we show here that an individualised programme with realistic goals, in which the type and the setting of the exercise vary, results in good compliance and a substantial increase in physical fitness and that the resulting beneficial effects on abdominal fat and cardiovascular risk factors were of the same magnitude even in older patients.

Accumulation of abdominal fat is associated with a multitude of metabolic complications such as glucose intolerance, hyperinsulinaemia, diabetes, and with changes in plasma triglyceride and HDL-C concentrations, as well as hypertension [12]. These changes contribute to the cardiovascular risk that is associated with an altered body fat distribution. This study shows that even moderate aerobic exercise training results in a considerable decrease in whole body fat, particularly in a reduction of abdominal fat, measured as the WHR. In epidemiological studies the WHR has proven to constitute a strong and independent cardiovascular risk factor. Besides, WHR and visceral fat mass are more closely correlated to total mortality, mortality from CHD and other cardiovascular risk factors than traditional measures of adiposity in both men and women [13, 14]. In our study the decrease in body fat was not accompanied by a loss of body weight, supporting the notion that people with large body fat stores are somewhat "protected" from losing lean body mass as weight is lost. Individuals whose weight is maintained during exercise gain almost twice as much lean body mass and lose more fat than do thinner persons [15]. 
The decrease in abdominal fat was paralleled by marked changes of the lipid profile in the intervention group with a highly significant increase in total HDL-C by $23 \%$ and in HDL3-C by $26 \%$ together with a decrease in triglyceride levels of $20 \%$. This positive effect on plasma lipids was maintained even to follow-up at 6 months, with a gradual increase of the HDL2-C subfraction. Cross-sectional studies have provided evidence for a beneficial effect of physical activity that is most consistent for total HDL-C and HDL2-C [16]. However, results from prospective surveys and intervention studies are equivocal. Five of eight exercise trials conducted among men [17] showed significant increases in HDL-C with exercise. Three of these trials evaluated the effect of exercise in women, but no significant differences were reported. A possible source of the discrepancy between studies is the inconsistent evaluation of regulators of lipoprotein metabolism other than physical activity such as insulin action, body composition (body weight, central adipose tissue), alcohol consumption and cigarette smoking. In the present study both the intervention and control group were matched with regard to these variables. In the non-diabetic population the changes in HDL-C induced by physical activity were generally thought to be due to increases in HDL2-C. There are, however, several reports in which HDL3-C was higher in active compared with inactive subjects, while there was no difference in HDL2-C by activity levels [18. 19]. To our knowledge no study has investigated the effects of physical activity on HDL-C subfractions in NIDDM patients. The present study shows that in untrained insulin-resistant NIDDM patients the initial change takes place in the HDL3-C subfraction with no changes in the HDL2-C subfraction. However, later on - at the 6-month follow-up - when the level of physical activity is maintained, HDL2-C starts to increase and HDL3-C decreases.

The mechanisms behind the increase in HDL3-C by physical activity are not clear. Serum HDL-C levels are regulated by the lipolytic enzymes, lipoprotein lipase (LPL) and hepatic lipase, by cholesterol ester transfer protein, and lecithin-cholesterol acyl-transferase. Since cholesterol ester transfer protein was not changed by physical activity and diet [20], a likely explanation would be an initial increase in hepatic lipase activity alone or in association with a decreased LPL activity $[21,22]$. A low LPL activity is a common finding in NIDDM, although exercise is generally thought to increase LPL activity. Whatever the reason, both the HDL2-C and HDL3-C subfractions are inversely related to the risk for myocardial infarction $[23,24]$. Since data in several epidemiological studies (e.g., Framingham Heart Study, Multiple Risk Factor Intervention Trial) were consistent with a $2-3 \%$ decrease in CHD risk for each $0.03 \mathrm{mmol} / 1$ increase in total HDL-C levels [25], the observed increase in to- tal HDL-C levels of $0.27 \mathrm{mmol} / \mathrm{l}$ represents a major reduction of the CHD risk.

In this study a highly significant reduction in diastolic and systolic blood pressure could be demonstrated while measuring blood pressure at clinic visits, as well as with ABPM, which is better correlated with target-organ damage from hypertension than clinic readings [26]. A reduction of both systolic and diastolic BP to the normal range is particularly important in diabetic patients prone to develop nephropathy [27].

Several studies have shown that increased physical activity combined with dietary intervention ameliorates blood glucose level control and can, but does not necessarily, result in weight reduction $[20,28$, 29 ]. In our 3-month trial the increase in physical activity without additional dietary intervention produced no significant changes of glycaemic control or body weight, which is in accordance with the reported difference in the metabolic response to exercise between younger and older NIDDM patients. As reviewed by Zierath and Wallberg-Henriksson [4], improved glycaemic control is generally achieved by younger patients with NIDDM, whereas, as in our study, the older age groups do not improve glycaemic control due to exercise. In addition, beneficial effects of exercise programmes are often underestimated, because changes in body weight may not necessarily reflect improvements in body composition. Also in our study, lean body mass increased while the fat mass, particularly the abdominal fat, decreased.

The programme of moderate exercise used in our study was acceptable to and generally enjoyed by the majority of patients regardless of adiposity, age or gender, and may prove to be realistic for a large proportion of sedentary people. The substantial improvement in physical fitness and the good compliance achieved by the exercisers suggest important health benefits for both young and older adults with NIDDM. Because pharmacological treatment options to improve the lipid profiles of individuals with diabetes appear to be limited and glycaemic control alone is often insufficient to control diabetic dyslipidaemia [30], lifestyle modifications such as physical activity remain preferable. Besides, as shown here, establishment of a permanent exercise routine improves the majority of cardiovascular risk factors associated with NIDDM or male-type fat distribution without the use of additional drug therapy.

Acknowledgements. We thank Professor W. Vetter and Ms. D. Holm for their assistance in recording ambulatory blood pressure. 


\section{References}

1. Stamler J, Vaccaro O, Neaton JD, Wentworth D (1993) Diabetes, other risk factors, and 12-yr cardiovascular mortality for men screened in the Multiple Risk Factor Intervention Trial. Diabetes Care 16: 434-444

2. Alberti KGMM, Gries FA (1988) Management of non-insulin-dependent diabetes mellitus in Europe: a consensus view. Diabet Med 5: 275-281

3. Schneider SH, Khachadurian AK, Amorosa LF, Clemow L, Ruderman NB (1992) Ten-year experience with an exercise-based outpatient life-style modification program in the treatment of diabetes mellitus. Diabetes Care 15: $1800-1810$

4. Zierath JR, Wallberg Henriksson H (1992) Exercise training in obese diabetic patients. Special considerations. Sports Med 14: 171-189

5. Barnard RJ, Lattimore L, Holly RG, Cherny S, Pritikin N (1982) Response of non-insulin-dependent diabetic patients to an intensive program of diet and exercise. Diabetes Care 5: 370-374

6. Conway JM, Norris KH, Bodwell CE (1984) A new approach for the estimation of body composition: infrared interactance. Am J Clin Nutr 40: 1123-1130

7. Golding LA, Myers CR, Sinning WE (1989) Y's way to physical fitness: the complete guide to fitness testing and instruction, 3rd edn. Champaign, USA: Human Kinetics, pp 106-108

8. Schneider SH, Ruderman NB (1990) Exercise and NIDDM. Diabetes Care 13: 785-789

9. Warnick GR, Benderson J, Albers JJ (1982) Dextran sulfate- $\mathrm{Mg} 2$ + precipitation procedure for quantitation of high-density-lipoprotein cholesterol. Clin Chem 28: 1379_ 1388

10. Patsch W, Brown SA, Morrisett JD, Gotto AM Jr, Patsch JR (1989) A dual-precipitation method evaluated for measurement of cholesterol in high-density lipoprotein subfractions HDL2 and HDL3 in human plasma. Clin Chem 35: $265-270$

11. Skarfors ET, Wegener TA, Lithell H, Selinus I (1987) Physical training as treatment for type 2 (non-insulin-dependent) diabetes in elderly men. A feasibility study over 2 years. Diabetologia 30: 930-933

12. Kissebah AH, Peiris AN (1989) Biology of regional body fat distribution: relationship to non-insulin-dependent diabetes mellitus. Diabetes Metab Rev 5: 83-109

13. Larsson B, Svardsudd K, Welin L, Wilhelmsen L, Bjorntorp P, Tibblin G (1984) Abdominal adipose tissue distribution, obesity, and risk of cardiovascular disease and death: 13-year follow up of participants in the study of men born in 1913. BMJ Clin Res Ed 288: 1401-1404

14. Lapidus L, Bengtsson C, Larsson B, Pennert K, Rybo E, Sjostrom L (1984) Distribution of adipose tissue and risk of cardiovascular disease and death: a 12 year follow-up of participants in the population study of women in Gothenburg, Sweden. BMJ Clin Res Ed 289: 1257-1261

15. Forbes GB (1991) Exercise and body composition. J Appl Physiol 70: 994-997

16. Mayer EJ, Burchfiel CM, Eckel RH, Marshall JA, Haskell WL, Hamman RF (1991) The role of insulin and body fat in associations of physical activity with lipids and lipoproteins in a biethnic population. The San Luis Valley Diabetes Study. Arterioscler Thromb 11: 973-984

17. Brownell KD, Bachorik PS, Ayerle RS (1982) Changes in plasma lipid and lipoprotein levels in men and women after a program of moderate exercise. Circulation 65: 477-484

18. Robinson D, Ferns GA, Bevan EA, Stocks J, Williams PT, Galton DJ (1987) High density lipoprotein subfractions and coronary risk factors in normal men. Arteriosclerosis 7: 341-346

19. Regensteiner JG, Mayer EJ, Shetterly SM, et al (1991) Relationship between habitual physical activity and insulin levels among nondiabetic men and women. San Luis Valley Diabetes Study. Diabetes Care 14: 1066-1074

20. Drexel H, Pfister R, Mitterbauer G et al (1992) Postprandial lipid and glucose metabolism in women undergoing moderate weight loss by diet plus exercise. Nutr Metab Cardiovase Dis 2: 159-164

21. Patsch JR, Prasad S, Gotto AM Jr, Patsch W (1987) High density lipoprotein -2 . Relationship of the plasma levels of this lipoprotein species to its composition, to the magnitude of postprandial lipemia, and to the activities of lipoprotein lipase and hepatic lipase. J Clin Invest 80: 341-347

22. Patsch JR, Prasad S, Gotto AM Jr, Bengtsson Olivecrona G (1984) Postprandial lipemia. A key for the conversion of high density lipoprotein2 into high density lipoprotein 3 by hepatic lipase. J Clin Invest 74: 2017-2023

23. Gaziano JM, Buring JE, Breslow JL et al. (1993) Moderate alcohol intake, increased levels of high-density lipoprotein and its subfractions, and decreased risk of myocardial infarction. N Engl J Med 329: 1829-1834

24. Stampfer MJ, Sacks FM, Salvini S, Willett WC, Hennekens CH (1991) A prospective study of cholesterol, apolipoproteins, and the risk of myocardial infarction. $\mathrm{N}$ Engl J Med 325: $373-381$

25. NIH Consensus Development Panel (1993) Triglyceride, high-density lipoprotein, and coronary heart disease. JAMA 269: 505-510

26. Perloff D, Sokolow M (1990) Ambulatory blood pressure: the San Francisco experience. J Hypertens Suppl 8: S105S111

27. Parving HH, Andersen AR, Smidt UM, Svendsen PA (1983) Early aggressive antihypertensive treatment reduces rate of decline in kidney function in diabetic nephropathy. Lancet 1: 1175-1179

28. Bogardus C, Ravussin E, Robbins DC, Wolfe RR, Horton ES, Sims EA (1984) Effects of physical training and diet therapy on carbohydrate metabolism in patients with glucose intolerance and non-insulin-dependent diabetes mellitus. Diabetes 33: 311-318

29. Eriksson KF, Lindgärde F (1991) Prevention of type 2 (non-insulin-dependent) diabetes mellitus by diet and physical exercise. The 6-year Malmö feasibility study. Diabetologia 34: 891-898

30. Baynes C, Elkeles RS, Henderson AD, Richmond W, Johnston DG (1993) The effects of glibenclamide on glucose homeostasis and lipoprotein metabolism in poorly controlled type 2 diabetes. Horm Metab Res 25: 96-101 